\title{
Clinico-microbiological study and antibiotic resistance profile of mecA and ESBL gene prevalence in patients with diabetic foot infections
}

\author{
WAQAS NASIR CHAUDHRY, RABIA BADAR, MUHSIN JAMAL, \\ JASON JEONG, JAMAL ZAFAR and SAADIA ANDLEEB \\ Department of Industrial Biotechnology, Atta-ur-Rahman School of Applied Biosciences, \\ National University of Sciences and Technology, Islamabad 44000, Pakistan
}

Received October 13, 2014; Accepted October 13, 2015

DOI: 10.3892/etm.2016.2996

\begin{abstract}
Diabetic foot infections (DFIs) constitute a major complication of diabetes mellitus. DFIs contribute to the development of gangrene and non-traumatic lower extremity amputations with a lifetime risk of up to $25 \%$. The aim of the present study was to identify the presence of neuropathy and determine the ulcer grade, microbial profile and phenotypic and genotypic prevalence of the methicillin-resistance gene mecA and extended spectrum $\beta$-lactamase (ESBL)-encoding genes in bacterial isolates of DFI in patients registered at the Pakistan Institute of Medical Sciences (Islamabad, Pakistan). The results indicated that $46 / 50$ patients (92\%), exhibited sensory neuropathy. The most common isolate was Staphylococcus aureus (25\%), followed by Pseudomonas aeruginosa (P. aeruginosa; 18.18\%), Escherichia coli (16.16\%), Streptococcus species (spp.) (15.15\%), Proteus spp. (15.15\%), Enterococcus spp. (9\%) and Klebsiella pneumoniae (K. pneumoniae; 3\%). The prevalence of the mecA gene was found to be $88 \%$ phenotypically and $84 \%$ genotypically. K. pneumoniae was shown to have the highest percentage of ESBL producers with a prevalence of $66.7 \%$ by double disk synergy test, and $100 \%$ by the cefotaxime + clavulanic acid/ceftazidime + clavulanic acid combination disk test. $P$. aeruginosa and $K$. pneumoniae had the highest (100\%) proportion of metallo $\beta$-lactamase producers as identified by the EDTA combination disk test. The overall prevalence of $\beta$-lactamase (bla)-CTX-M, bla-CTX-M-15, bla-TEM, bla-OXA and bla-SHV genes was found to be 76.9, 76.9, 75.0, 57.7 and $84.6 \%$, respectively, in gram-negative DFI isolates. The prevalence of mecA and ESBL-related genes was found to be
\end{abstract}

Correspondence to: Dr Saadia Andleeb, Department of Industrial Biotechnology, Atta-ur-Rahman School of Applied Biosciences, National University of Sciences and Technology, Sector H-12, Kashmir Highway, Islamabad 44000, Pakistan

E-mail: saadiamarwat@yahoo.com

Key words: diabetic foot ulcer, prevalence, antibiotic resistance, extended spectrum $\beta$-lactamase alarmingly high in DFIs, since these genes are a major cause of antibiotic treatment failure.

\section{Introduction}

Diabetes, including Type I and Type II, is the most common non-communicable disease (NCD), with an overall prevalence of $8.3 \%$ worldwide, and is the fourth or fifth leading cause of mortality in developed countries $(1,2)$. Type II diabetes accounts for the majority $(>85 \%)$ of the total diabetes prevalence (3). It is estimated that $15-25 \%$ of patients with diabetes will develop a diabetic foot ulcer (DFU) at some point during their lifetime (1), and this includes patients with Type I or Type II diabetes (4). According to the International Diabetic Federation Report of 2005 (5), 85\% of diabetes-related lower extremity amputations were preceded by DFUs.

Hyperglycemia causes microvascular complications, including neuropathy, retinopathy and nephropathy (6). The primary function of normal, intact skin is to control microbial populations that live on the skin surface and to prevent underlying tissues from becoming colonized and invaded by potential pathogens (7). In diabetes, a loss of sensation in the lower extremities may occur, which is known as neuropathy (8). Neuropathic individuals are highly prone to physical injuries in their lower extremities (9). Any such injury is a potential cause of a DFU, since hyperglycemia reduces blood flow and the phagocytic activity of neutrophils and macrophages (10). The most grave consequence of DFUs is limb amputation, which occurs 10-30 times more frequently in patients with diabetes than in the general population (46.1-9,600 individuals $/ 10^{5}$ vs. 5.8-31 individuals $/ 10^{5}$, respectively) (11-13). The mortality rates following amputation are $13-40 \%$ in the first year, $35-65 \%$ in the first 3 years, and $39-80 \%$ in the first 5 years (14).

In addition to the maintenance of glycemic control, surgical debridement, wound care, pressure offloading and adequate blood flow maintenance, it is also important to evaluate the type of microorganisms in infected wounds (15). Infection can convert simple injuries to gangrene and cause osteomyelitis, leading to lower extremity amputation (16). The majority of mild infections are monomicrobial and caused by 
aerobic gram-positive cocci, such as Staphylococcus aureus (S. aureus) and Streptococcus species (spp.). By contrast, the most severe infections are polymicrobial and caused by aerobic gram-positive cocci, gram-negative bacilli and anaerobes $(17,18)$.

The emergence of antibiotic resistance in infecting bacteria can complicate and prolong the treatment regime, and may even cause chronic wounds to become gangrenous (19). It is noteworthy that methicillin-resistant $S$. aureus (MRSA) infections are associated with a higher mortality rate compared with methicillin-susceptible $S$. aureus infections (20). The mecA gene, which is responsible for methicillin resistance, encodes an altered penicillin-binding protein $\left(\mathrm{PBP}_{2 \mathrm{~A}}\right)$ with a low affinity for $\beta$-lactam antibiotics $(21,22)$. Extended spectrum $\beta$-lactamases (ESBLs) are a group of enzymes encoded by genes that are common among Enterobacteriaceae (23). Most ESBLs are mutants of Temoneira (TEM)-, sulfhydryl variable (SHV)- and cefotaximase (CTX-M)-type lactamases, which hydrolyze cefotaxime and ceftriaxone, and are weakly active against ceftazidime (24,25). Metallo $\beta$-lactamases (MBLs), which require divalent cations, usually zinc, as metal cofactors for enzyme activity, are very broad spectrum $\beta$-lactamases with the ability to hydrolyze virtually all classes of $\beta$-lactams, including extended spectrum cephalosporins and carbapenems (26).

Genetic variations and the high incidence of resistance genes in microbes hinder the control of infections in DFUs and have an important role in the manifestation of the disease (27). It is therefore important to investigate the prevalence of these genes in patients with DFUs in order to facilitate the prompt control of infection. The aim of the present study was to investigate the phenotypic and genotypic prevalence of mecA and ESBLs in bacteria isolated from DFU samples.

\section{Materials and methods}

Sample size and inclusion and exclusion criteria. In total, 50 diabetic patients with DFU were included in the study between January 21, 2013 and July 20, 2013. The study was approved by the Ethics Committee and Institutional Review Board of the Atta-ur-Rahman School of Applied Biosciences (Islamabad, Pakistan). Patients of all ages and genders with type 2 diabetes with a foot infection or DFU who visited the Diabetic Foot Clinic and Out-Patient Department of Pakistan Institute of Medical Sciences (Islamabad, Pakistan) were included. The exclusion criteria were as follows: Non-diabetic patients with foot infection, diabetic patients that had previously received antibiotic treatment, patients with type 1 diabetes with foot infection, and DFUs with a duration of $>3$ weeks. Information on the duration of the diabetes and DFUs, glycemic control, and history of previous hospitalization due to the DFU was obtained from all patients. The patients were examined for the presence of sensory neuropathy and peripheral vascular disease by measuring the ankle brachial index. The foot ulcers were classified according to the New University of Texas classification system (28).

Isolation, identification and antimicrobial susceptibility testing of the microbes. Cultures of the specimens were obtained at the time of admission, after the surface of the wound had been washed vigorously with saline, followed by debridement of the superficial tissue from the exudates to avoid the isolation of colonizing flora. Bacteria were isolated through the inoculation of specimens on a set of selective and non-selective media, such as blood agar and MacConkey and chocolate agars (Difco; BD Biosciences, Franklin Lakes, NJ, USA). All inoculated plates were incubated at $37^{\circ} \mathrm{C}$ for 24-48 h. The bacterial isolates were identified using conventional biochemical tests.

The Kirby-Bauer disk diffusion method (29) was used for antibiotic susceptibility testing. The Clinical and Laboratory Standard Institute (CLSI) guidelines were followed for the selection of media, inoculum turbidity and preparation of media plates along with the application of disks and the interpretation of the zone of inhibition. Suspension was inoculated on the media plate with the assistance of a sterile glass spreader. Oxoid $^{\mathrm{TM}}$ antibiotic disks (Thermo Fisher Scientific, Inc., Waltham, MA, USA) were applied using sterile forceps. The zone of inhibition around the tested antibiotics was measured, and interpretations were made using the breakpoints elaborated in the CLSI guidelines (30).

Phenotypic detection of ESBL. Isolates that showed intermediate resistance to third-generation cephalosporin were screened to detect ESBL production. A double disk synergy test (DDST) was performed for the phenotypic detection of ESBL production (31). A third-generation cephalosporin disk was placed on the plate with another disk containing amoxicillin + clavulanic acid; other combination disks, such as ampicillin + salbactam and piperacillin + tazobactam, were also tested. Plates were incubated at $37^{\circ} \mathrm{C}$ for 18-24 $\mathrm{h}$ and the shape of the zone of inhibition was noted. Isolates that exhibited a distinct potentiation towards the amoxicillin + clavulanic acid disk were considered potential ESBL producers. Escherichia coli (E. coli) ATCC 25922 and Klebsiella pneumoniae (K. pneumoniae) ATCC 700603 were used as negative and positive controls for ESBL, respectively. Phenotypic detection of MBLs was performed using an ethylenediaminetetraacetic acid (EDTA) disk synergy test (32). For this, an imipenem disk was placed on a plate inoculated with bacterial suspension, and $5 \mu 10.5 \mathrm{M}$ EDTA was poured on another imipenem disk and placed on the same plate; differences in the size of inhibition zone were then observed.

Molecular detection of antibiotic resistance genes. For the molecular detection of antibiotic resistance genes, the phenol-chloroform method was used to extract DNA from bacterial samples (33). Bacterial cells were grown in Luria Bertani broth overnight at $37^{\circ} \mathrm{C}$ and suspended in lysis buffer $(0.2 \mathrm{mg} / \mathrm{ml}$ proteinase $\mathrm{K}$ in $1 \%$ sodium dodecyl sulfate). The suspension was then incubated for $1 \mathrm{~h}$ at $55^{\circ} \mathrm{C}$ and DNA was extracted twice using phenol-chloroform. Subsequently, sodium acetate $(0.3 \mathrm{M})$ and cold ethanol were added to precipitate DNA. The precipitate was centrifuged (Sigma 1-14; Sigma Laborzentrifugen GmbH, Osterode am Harz, Germany) at $14,462 \times \mathrm{g}$ for $2 \mathrm{~min}$ at room temperature, after which the DNA pellet was suspended in $100 \mu 1$ Tris-EDTA buffer. mecA, $\beta$-lactamase (bla)-SHV, bla-CTX-M, bla-CTX-M-15, bla-TEM and bla-oxacillinase (OXA) genes were detected 
Table I. Primer sequences of mecA and extended spectrum $\beta$-lactamase genes.

\begin{tabular}{lclccc}
\hline Target gene & Primer & \multicolumn{1}{c}{ Sequence $\left(5^{\prime}-3^{\prime}\right)$} & Tm, ${ }^{\circ} \mathrm{C}$ & GC, $\%$ & Ref. \\
\hline bla-SHV & $\mathrm{F}$ & CTTTATCGGCCCTCACTCAA & 60.4 & 50 & $(25)$ \\
& $\mathrm{R}$ & AGGTGCTCATCATGGGAAAG & 60.4 & 50 & \\
bla-OXA & $\mathrm{F}$ & GGCACCAGATTCAACTTTCAAG & 60.8 & 45 & $(26)$ \\
& $\mathrm{R}$ & GACCCCAAGTTCCTGTAAGTG & 62.7 & 50 & \\
bla-CTX-M & $\mathrm{F}$ & ATGTGCAGTACCAGTAAAGTGATGGC & 64.6 & 46 & $(27)$ \\
& $\mathrm{R}$ & TGGGTAAAATAAGTCACCAGAATCAGCGG & 66 & 45 & \\
bla-TEM & $\mathrm{F}$ & CGCCGCATACACTATTCTCAGAATGA & 64.6 & 46 & $(28)$ \\
& $\mathrm{R}$ & ACGCTCACCGGCTCCAGATTTAT & 64.6 & 52 & \\
bla-CTX-M-15 & $\mathrm{F}$ & AGGCAGACTGGGTGTGGCAT & 64.5 & 60 & \\
& $\mathrm{R}$ & TTACCCAGCGTCAGATTCCG & 62.4 & 55 & \\
mecA & $\mathrm{F}$ & GTAGAAATGACTGAACGTCCGATAA & 54.4 & 40 & \\
& $\mathrm{R}$ & ATTGGCCAATTCACATTGTTCG & 54 & 42 & \\
\hline
\end{tabular}

bla, $\beta$-lactamase; SHV, sulfhydryl variable; OXA, oxacillinase; CTX-M, cefotaximase; TEM, Temoneira; F, forward; R, reverse; Ref., reference; Tm, melting temperature; GC, GC nucleotide content.

Table II. Stages and grades of DFU in the patients according to the University of Texas Classification System (19).

\begin{tabular}{lrrrr}
\hline & \multicolumn{3}{c}{ DFU grade } & \\
\cline { 2 - 4 } Stage of ulcer & \multicolumn{1}{c}{ I } & II & III & Total \\
\hline A & 0 & 0 & 0 & 0 \\
B & 11 & 16 & 7 & 34 \\
C & 2 & 1 & 0 & 3 \\
D & 1 & 5 & 7 & 13 \\
Total & 14 & 22 & 14 & 50 \\
\hline
\end{tabular}

DFU, diabetic foot ulcer.

using polymerase chain reaction (PCR). For PCR, a total reaction mixture volume of $25 \mu \mathrm{l}$ was prepared containing $2 \mathrm{mM}$ deoxyribonucleotide triphosphates, 10X PCR buffer, $50 \mathrm{mM}$ $\mathrm{MgCl}_{2}, 50 \mathrm{pM}$ of each primer, $5 \mu \mathrm{l}$ DNA sample, 1 unit of thermo stable Taq DNA polymerase (Fermentas; Thermo Fisher Scientific, Inc., Waltham, MA, USA) and nuclease-free water to adjust the final volume. The reaction mixture was centrifuged (Sigma 1-14; Sigma Laborzentrifugen $\mathrm{GmbH}$ ) at $14,462 \mathrm{x} g$ for $30 \mathrm{secs}$ at room temperature for thorough mixing. Subsequently, PCR was conducted using the Swift ${ }^{\mathrm{TM}}$ MaxPro thermal cycler (Applied Biosystems; Thermo Fisher Scientific, Inc., Foster City, USA). The primer sequences are presented in Table I (34-37). The PCR products were separated by $1 \%$ agarose gel electrophoresis, in which a 100 bp DNA ladder was used as a reference (Invitrogen; Thermo Fisher Scientific, Inc.).

\section{Results}

Neuropathy and ulcer grade. A total of 50 patients fulfilled the inclusion criteria and were included in the study. Out of

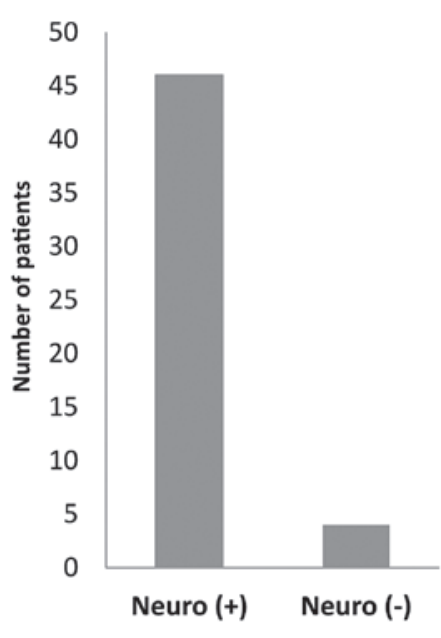

Figure 1. Prevalence of sensory neuropathy in diabetic foot ulcer patients. There were 46 patients $(92 \%)$ with sensory neuropathy [Neuro (+)] and 4 patients $(8 \%)$ without [Neuro $(-)]$.

those 50 subjects, 29 (58\%) were men and 21 (42\%) women (age range, 36-80 years; mean age, 58 years). According to the University of Texas Classification, 11 patients had stage-B grade-I ulcer, 16 had stage-B grade-II ulcer, 7 had stage-B grade-III ulcer, 2 had stage- $C$ grade-I ulcer, 1 had stage-C grade-II, 1 had stage-D grade-I ulcer, 5 had stage-D grade-II ulcer and 7 had stage-D grade-III ulcer (Table II). The specimens containing clinically significant pathogens included wound swabs $(37 / 50 ; 74 \%)$, tissue $(7 / 50 ; 14 \%)$, pus $(4 / 50 ; 8 \%)$ and bone $(2 / 50 ; 4 \%)$. Of the 50 patients, 46 patients $(92 \%)$ had sensory neuropathy while 4 patients (8\%) did not (Fig. 1).

Microbiology and antimicrobial susceptibility testing of diabetic foot wounds sample. A total of 99 bacterial isolates were obtained from the 50 patients with DFUs. In these patients, gram-negative bacilli $(59.59 \%)$ were isolated more frequently than gram-positive cocci $(40.4 \%)$. The 


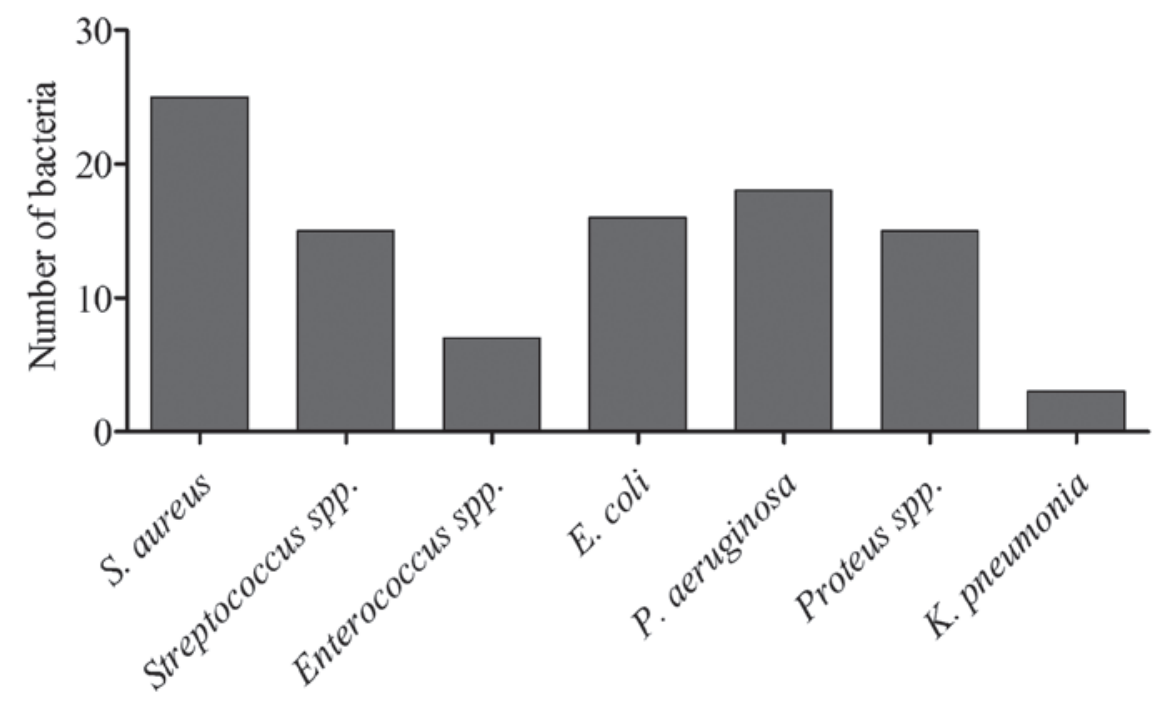

Figure 2. Microbiology of DFUs. Distribution of microbes isolated from DFU samples. DFU, diabetic foot ulcer; SA, Staphylococcus aureus; E. coli, Escherichia coli; PA, Pseudomonas aeruginosa; KP, Klebsiella pneumoniae; spp, species.

most common isolate was S. aureus $(25 \%)$, followed by Pseudomonas aeruginosa (P. aeruginosa; $18.18 \%$ ) and E. coli $(16.16 \%)$. The other isolated organisms were Streptococcus spp. (15.15\%), Enterococcus spp. (9\%), Proteus spp. (15.15\%) and K. pneumoniae (3\%) (Fig. 2). Single organisms were isolated from 14 samples $(28 \%)$ and mixed bacterial growths were identified in 36 samples $(72 \%)$. The details of the organisms isolated from the infected foot lesions are presented in Fig. 2. The mean number of isolates per culture-positive sample was 1.9 .

All S. aureus isolates were resistant to penicillin, out of which $90 \%$ exhibited resistance against oxacillin, cefoxitin and ceftazidime. Vancomycin showed inhibitory effects for only $20 \%$ of the $S$. aureus isolates. By contrast, $100 \%$ of the Streptococcus spp. isolates exhibited resistance to oxicillin, cefotaxime, ceftriaxone, cefepime, cefoxitin, ceftazidime and penicillin, while $40 \%$ showed susceptibility to vancomycin. According to the sensitivity data, $70 \%$ of the $S$. aureus and $80 \%$ of Streptococcus spp. isolates were multidrug-resistant (Table III). All P. aeruginosa and K. pneumoniae isolates, as well as $83.33 \%$ of the Proteus spp. and $75 \%$ of the $E$. coli isolates were found to be resistant to ceftazidime. All gram-negative isolates exhibited high susceptibility to chloramphenicol and meropenem. K. pneumoniae and P. aeruginosa were found to be the most resistant, with $>60 \%$ of strains exhibiting antibiotic resistance, whereas for Proteus spp. and E. coli, $<55 \%$ of strains were resistant (Table IV).

Phenotypic and genotypic detection of MRSA and ESBL. The phenotypic prevalence of the mecA gene was found to be $88 \%$. No inhibition zone was observed around the $30-\mu \mathrm{g}$ cefoxitin disk. Out of $25 \mathrm{~S}$. aureus strains, 21 were found to be positive for the mecA gene PCR, with an overall prevalence of 84\%. DDST results showed that 66.66, 33.33, 66.7 and 50\% of the Proteus spp., P. aeruginosa, K. pneumoniae and E. coli populations, respectively, were ESBL producers. In the case of the cefotaxime + clavulanic acid/ceftazidime + clavulanic acid combination disk test for ESBL detection, a >5-mm increase was observed in the size of the zone of inhibition around the
Table III. Antibiotic resistance (\%) pattern of gram-positive bacteria.

Antibiotics S. aureus Streptococcus spp.

\begin{tabular}{lrr}
\hline Oxicillin & 90 & 100 \\
Cefotaxime & 80 & 100 \\
Ceftriaxone & 80 & 100 \\
Cefepime & 70 & 100 \\
Cefoxitin & 90 & 100 \\
Ceftazidime & 90 & 100 \\
Aztreonam & 30 & 80 \\
Imepenem & 50 & 80 \\
Gentamicin & 30 & 0 \\
Cefoperazone & 50 & 60 \\
Amoxicillin + clavulanic acid & 40 & 60 \\
Ampicillin + sulbactam & 30 & 60 \\
Tazobactam + piperacillin & 0 & 40 \\
Chloramphenicol & 0 & 20 \\
Penicillin & 100 & 60 \\
Vancomycin & 80 &
\end{tabular}

S. aureus, Staphylococcus aureus; spp., species.

cefotaxime or ceftazidime disk containing the ESBL inhibitor clavulanic acid, as compared with the simple cefotaxime or ceftazidime disk. According to the cefotaxime + clavulanic acid/ceftazidime + clavulanic acid combination disk test, $K$. pneumoniae and $E$. coli had the highest prevalence (100\%) of ESBL producers, while the EDTA disk synergy test confirmed $P$. aeruginosa and $K$. pneumoniae as having the highest prevalence of MBL producers; $E$. coli was found to have the lowest prevalence, with only $37 \%$ of strains producing MBL (Table V).

PCR showed that all K. pneumoniae and E. coli isolates were positive for bla-CTX-M, bla-CTX-M-15, bla-TEM, 

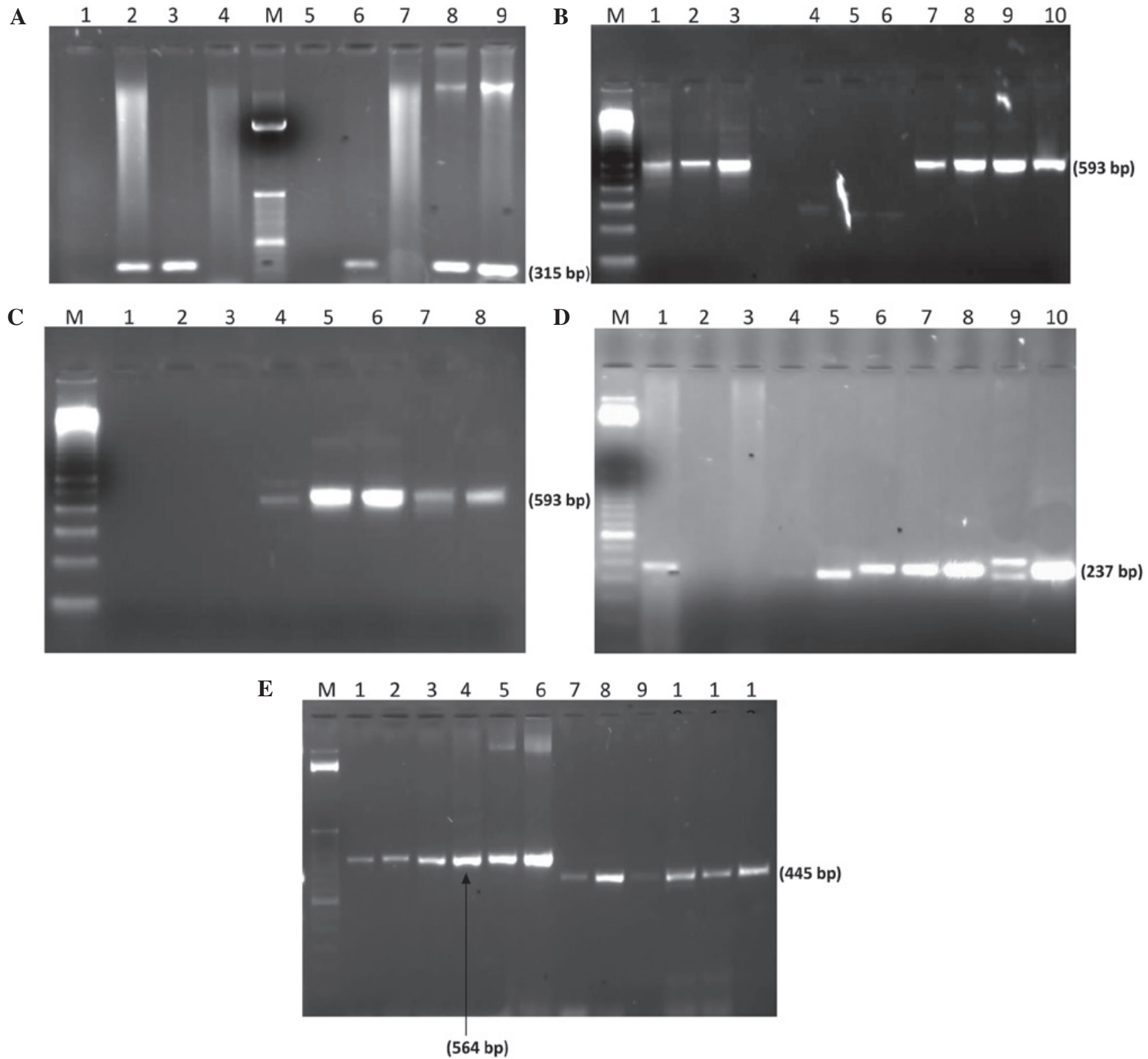

Figure 3. Molecular detection of antibiotic resistance genes. (A) PCR amplification of mecA gene: Lane M; 100 bp ladder (Invitrogen); lane 1, negative control (K. pneumoniae ATCC BAA-1144); lane 2, positive control (S. aureus ATCC BAA-1026); lanes 3, 6, 8 and 9, mecA gene expression in S. aureus. (B) PCR amplification of bla-CTXM gene: Lane M, 100 bp Ladder; lane 1, Proteus spp.; lanes 2 and 3, E. coli; lane 7, P. aeruginosa; lanes 8-11, K. pneumoniae. (C) PCR amplification of bla-CTXM-15 gene: Lane M, 100 bp ladder; lane 1, negative control (K. pneumoniae ATCC BAA-1144); lane 4, P. aeruginosa; lanes 5 and 6, E. coli; lane 7, K. pneumoniae; lane 8, Proteus spp. (D) PCR amplification of bla-SHV gene: Lane M, 50 bp ladder (Invitrogen); lane 10, positive control (K. pneumoniae ATCC 700603); lane 2, negative control (E. coli ATCC 25922); lane 5, P. aeruginosa; lanes 6-8, E. coli; lanes 9 and 10, K. pneumoniae. (E) PCR amplification of bla-TEM and bla-OXA genes: Lane M; 50 bp ladder; lane 1, Proteus spp.; lane 2, P. aeruginosa; lanes 3 and 4, K. pneumoniae; lanes 5 and 6, E. coli; lane 7, Proteus spp.; lane 8,P.aeruginosa; lanes 9 and 10, K.pneumoniae; lane 11 and 12, E. coli. PCR, polymerase chain reaction; bla, $\beta$-lactamase; CTX-M, cefotaximase; SHV,sulfhydryl variable; TEM, Temoneira; OXA, oxacillinase; ATCC, American Type Culture Collection; K. pneumoniae, Klebsiella pneumoniae, S. aureus, Staphylococcus aureus; P. aeruginosa, Pseudomonas aeruginosa; E. coli, Escherichia coli, spp., species.

bla-OXA and bla-SHV resistance genes (Fig. 3). In addition, $72.2 \%$ of the $P$. aeruginosa strains were positive for bla-SHV and $66.7 \%$ for bla-CTX-M, bla-CTX-M-15 and bla-TEM. However, only $33.3 \%$ of the $P$. aeruginosa strains were positive for the bla-OXA gene. In Proteus spp., the resistance gene with the highest prevalence $(80 \%)$ was bla-SHV (Table VI).

\section{Discussion}

The high occurrence of DFUs and amputation within the diabetic population has become an increasingly alarming public health concern in the developed and developing worlds (38). These complications begin with neuropathy, which occurs as a result of hyperglycemia and involves a loss of sensation in the lower extremities (8). Neuropathic individuals are highly prone to physical injuries in their lower extremities (9), which lead to diabetic foot infections (DFIs), which in turn may result in the amputation of the lower extremities and subsequent mortality (11-13). DFUs impose a tremendous medical and financial burden on the health care system in the USA, with a cost as high as $\$ 45,000$ per patient; in addition, the impaired mobility and substantial 
Table IV. Antibiotic resistance (\%) pattern of gram-negative bacteria.

\begin{tabular}{|c|c|c|c|c|}
\hline Antibiotics & K. pneumoniae & P. aeruginosa & Proteus spp. & E. coli \\
\hline Oxicillin & 100 & 66.7 & 83.3 & 50 \\
\hline Cefotaxime & 80 & 100 & 83.3 & 75 \\
\hline Ceftriaxone & 100 & 100 & 100 & 50 \\
\hline Cefepime & 100 & 100 & 83.3 & 50 \\
\hline Cefoxitin & 80 & 100 & 100 & 75 \\
\hline Ceftazidime & 100 & 100 & 83.3 & 75 \\
\hline Aztreonam & 60 & 33.3 & 50 & 50 \\
\hline Imepenem & 60 & 66.7 & 33.3 & 50 \\
\hline Cefoperazone & 60 & 100 & 66.7 & 50 \\
\hline Amoxicillin + clavulanic acid & 80 & 100 & 16.7 & 50 \\
\hline Ampicillin + sulbactam & 60 & 66.7 & 33.3 & 50 \\
\hline Tazobactam + piperacillin & 80 & 66.7 & 33.3 & 75 \\
\hline Amikacin & 60 & 33.3 & 33.3 & 25 \\
\hline Meropenim & 40 & 0 & 16.7 & 25 \\
\hline Chloramphenicol & 20 & 0 & 0 & 25 \\
\hline
\end{tabular}

K. pneumoniae, Klebsiella pneumoniae; P. aeruginosa, Pseudomonas aeruginosa; E. coli, Escherichia coli; spp., species.

Table V. Phenotypic detection of methicillin resistance, extended spectrum $\beta$-lactamase and metallo $\beta$-lactamase production (\%).

\begin{tabular}{lccr}
\hline $\begin{array}{l}\text { Bacterial } \\
\text { isolates }\end{array}$ & $\begin{array}{l}\text { Double disk } \\
\text { synergy test }\end{array}$ & $\begin{array}{c}\text { CTX + CL/CAZ + CL } \\
\text { combination disk test }\end{array}$ & $\begin{array}{c}\text { EDTA combinationt } \\
\text { disk test }\end{array}$ \\
\hline $\begin{array}{l}\text { Proteus spp. } \\
\text { P. aeruginosa }\end{array}$ & 66.7 & 73 & 80 \\
K. pneumoniae & 33.3 & 33 & 100 \\
E. coli & 66.7 & 100 & 100 \\
\hline
\end{tabular}

CTX, cefotaxime; CL, clavulanic acid; CAZ, ceftazidime; EDTA, ethylenediaminetetraacetic acid; P. aeruginosa, Pseudomonas aeruginosa; K. pneumoniae, Klebsiella pneumoniae; E. coli, Escherichia coli; spp., species.

Table VI. Molecular detection of extended spectrum $\beta$-lactamase production (\%).

\begin{tabular}{|c|c|c|c|c|c|}
\hline Bacterial isolates & bla-CTX-M & bla-CTX-M15 & bla-TEM & bla-OXA & bla-SHV \\
\hline Proteus spp. & 60 & 60 & 53.3 & 33.3 & 80 \\
\hline P. aeruginosa & 66.7 & 66.7 & 66.7 & 33.3 & 72.2 \\
\hline K. pneumoniae & 100 & 100 & 100 & 100 & 100 \\
\hline E. coli & 100 & 100 & 100 & 100 & 100 \\
\hline Total & 76.9 & 76.9 & 75 & 57.7 & 84.6 \\
\hline
\end{tabular}

bla, $\beta$-lactamase; CTX-M, cefotaximase; SHV, sulfhydryl variable; OXA, oxacillinase; TEM, Temoneira; P. aeruginosa, Pseudomonas aeruginosa; K. pneumoniae, Klebsiella pneumoniae; E. coli, Escherichia coli; spp., species.

loss of productivity associated with DFUs affects the quality of life of the patient (39).

Diabetic neuropathy, along with poor blood circulation in the lower extremities, nerve damage and foot wounds, constitutes one of the leading causes of DFUs (40), which is consistent with previous studies in which up to $92 \%$ of patients with DFUs also had neuropathy $(41,42)$. The treatment prognosis is exacerbated when an ulcer is infected with multiple microbes (43), since little is known about multi-species interactions or the ideal antibiotic regimen for the treatment 
of multi-species infections. In the present study gram-positive bacteria, including $S$. aureus, were observed to be dominant in these infections; which is consistent with previous reports $(44,45)$. The assays performed in the present study also identified high percentages of multidrug-resistant $P$. aerugi$n o s a$, which is troubling as $P$. aeruginosa is an aggressive gram-negative bacillus (46).

High rates of antibiotic resistance have previously been reported in patients with diabetes (47). Richard et al (48) found that the most common causative agent of DFIs, $S$. aureus, represented $36.5 \%$ of isolates from DFUs and, notably, $37.4 \%$ of these were MRSA. In the present study, however, it was found that $84 \%$ of $S$. aureus isolates were MRSA, while $20 \%$ were vancomycin resistant. S. aureus isolates have been associated with prolonged bacteremia, greater rates of infection-associated complications and vancomycin treatment failure (49). Among the K.pneumoniae isolates of the present study, a very high incidence of ESBL in the bacteria was detected by phenotypic testing $(100 \%$ by the cefotaxime + clavulanic acid/ceftazidime + clavulanic acid combination disk test), which is comparable with previous studies, where up to $97 \%$ prevalence has been reported $(50,51)$. The highest prevalence of $\mathrm{MBL}$ producers was found in P. aeruginosa and K. pneumoniae (100\% in the EDTA combination disk test). In a study from India, $74.5 \%$ of the ceftazidime-resistant $P$. aeruginosa isolates were found to be MBL producers (52). In another study from Iran, 53\% of the 94 ceftazidime resistant $P$. aeruginosa isolates were found to be MBL producers (53).

The PCR analysis conducted in the present study revealed that 21 out of $25 \mathrm{~S}$. aureus isolates $(84 \%)$ harbored the mecA gene, a considerably high proportion compared with that observed in the study by Bukhari et al (54), which found an MRSA prevalence of $41.9 \%$ in clinical isolates in Lahore, Pakistan. In addition, in the present study all K. pneumoniae and $E$. coli isolates were $100 \%$ positive for all ESBL genes. The high prevalence of the CTX-M gene in the present study was in concordance with the results of the study of Šeputiené et al (55), who reported CTX-M encoding genes in the majority of E. coli $(96 \%)$ and $K$. pneumoniae $(71 \%)$ isolates showing the ESBL phenotype. ESBL-positive E. coli isolates investigated in Sweden encoded mainly CTX-Ms (92\%), followed by TEM-type (63\%), OXA-type (59\%) and SHV-type (6\%) $\beta$-lactamases (34). According to a study by Bali et al (56), TEM-type ESBLs were found in $72.72 \%$ of E. coli and $75 \%$ of $K$. pneumoniae. A study conducted by Umadevi et al (57) observed that ESBL production in P. aeruginosa is less prevalent than that in Enterobacteriaceae, which is consistent with the results of the present study. This finding limits treatment options considerably, causing great concern regarding the lack of adequate treatment and the spread of mecA- and ESBL-carrying isolates in DFIs.

In conclusion, infections caused by multidrug-resistant bacteria that produce mecA and ESBL enzymes have been reported with an increasing frequency in DFIs and are associated with amputation. Epidemiological information helps in the design of better programs for infection control. Due to the resistance of DFIs to numerous antimicrobial agents, treatment can be challenging. Hence, it is recommended that active surveillance for ESBL-producing pathogens in populations at high-risk for DFUs is performed using appropriate antimicrobial techniques.

\section{Acknowledgements}

This study was supported by the Higher Education Commission and Ministry of Science and Technology of Pakistan. The authors would like to thank Mr. Muhammad Shafique from the Microbiology Laboratory of the Pakistan Institute of Medical Sciences, for generously helping with the isolation and characterization of bacterial strains from DFU samples.

\section{References}

1. Singh N, Armstrong DG and Lipsky BA: Preventing foot ulcers in patients with diabetes. JAMA 293: 217-228, 2005.

2. Mutlu F, Bener A, Eliyan A, Delghan H, Nofal E, Shalabi L and Wadi N: Projection of Diabetes Burden through 2025 and Contributing Risk Factors of Changing Disease Prevalence: An Emerging Public Health Problem. J Diabetes Metab 5: 341, 2014.

3. Forouhi NG and Wareham NJ: Epidemiology of diabetes. Medicine 38: 602-606, 2010.

4. Cusick M, Meleth AD, Agrón E, Fisher MR, Reed GF Knatterud GL, Barton FB, Davis MD, Ferris FL and Chew EY; Early Treatment Diabetic Retinopathy Study Research Group: Associations of mortality and diabetes complications in patients with type 1 and type 2 diabetes: Early treatment diabetic retinopathy study report no. 27. Diabetes Care 28: 617-625, 2005.

5. Clayton W and Elasy TA: A Review of the Pathophysiology, Classification, and Treatment of Foot Ulcers in Diabetic Patients. Clin Diabetes: 27, 52-58, 2009.

6. Fowler MJ: Microvascular and macrovascular complications of diabetes. Clinical diabetes 26: 77-82, 2008.

7. Bowler PG, Duerden BI and Armstrong DG: Wound microbiology and associated approaches to wound management. Clin Microbiol Rev 14: 244-269, 2001.

8. Argoff CE, Cole BE, Fishbain DA and Irving GA: Diabetic peripheral neuropathic pain: Clinical and quality-of-life issues. Mayo Clin Proc 81 (Suppl 4): S3-S11, 2006.

9. Podwall D and Gooch C: Diabetic neuropathy: Clinical features, etiology, and therapy. Curr Neurol Neurosci Rep 4: 55-61, 2004.

10. Delamaire M, Maugendre D, Moreno M, Le Goff MC, Allannic H and Genetet B: Impaired leucocyte functions in diabetic patients. Diabet Med 14: 29-34, 1997.

11. Siitonen OI, Niskanen LK, Laakso M, Siitonen JT and Pyörälä K: Lower-extremity amputations in diabetic and nondiabetic patients: A population-based study in eastern Finland. Diabetes care 16: 16-20, 1993.

12. Trautner C, Haastert B, Giani G and Berger M: Incidence of lower limb amputations and diabetes. Diabetes care 19: 1006-1009, 1996.

13. Paneni F, Beckman JA, Creager MA and Cosentino F: Diabetes and vascular disease: Pathophysiology, clinical consequences, and medical therapy. Eur Heart J 34: 2436-2443, 2013.

14. Reiber GE: Epidemiology of foot ulcers and amputations in the diabetic foot. The diabetic foot 6: 13-32, 2001.

15. Tiwari S, Pratyush DD, Dwivedi A, Gupta SK, Rai M and Singh SK: Microbiological and clinical characteristics of diabetic foot infections in northern India. J Infec Dev Ctries 6: 329-332, 2012.

16. Lipsky B, Pecoraro R and Wheat L: The diabetic foot. Soft tissue and bone infection. Infect Dis Clin North Am 4: 409-432, 1990.

17. Frykberg RG: An evidence-based approach to diabetic foot infections. Am J Surg 186 (Suppl): S44-S54, 2003.

18. Benwan K, Al Mulla A and Rotimi VO: A study of the microbiology of diabetic foot infections in a teaching hospital in Kuwait. J Infect Public Health 5: 1-8, 2012.

19. Roberts RR, Hota B, Ahmad I, Scott RD 2nd, Foster SD, Abbasi F, Schabowski S, Kampe LM, Ciavarella GG, Supino M, et al: Hospital and societal costs of antimicrobial-resistant infections in a Chicago teaching hospital: Implications for antibiotic stewardship. Clin Infect Dis 49: 1175-1184, 2009.

20. Cosgrove SE, Sakoulas G, Perencevich EN, Schwaber MJ, Karchmer AW and Carmeli Y: Comparison of mortality associated with methicillin-resistant and methicillin-susceptible Staphylococcus aureus bacteremia: A meta-analysis. Clin Infect Dis 36: 53-59, 2003. 
21. Grundmann H, Aires-de-Sousa M, Boyce J and Tiemersma E: Emergence and resurgence of meticillin-resistant Staphylococcus aureus as a public-health threat. Lancet 368: 874-885, 2006.

22. Askari E, Soleymani F, Arianpoor A, Tabatabai SM, Amini A and Naderi Nasab M: Epidemiology of mecA-methicillin resistant Staphylococcus aureus (MRSA) in Iran: A systematic review and meta-analysis. Iran J Basic Med Sci 15: 1010-1019, 2012.

23. Poole K: Resistance to beta-lactam antibiotics. Cell Mol Life Sci 61: 2200-2223, 2004.

24. Bonnet R: Growing group of extended-spectrum beta-lactamases: The CTX-M enzymes. Antimicrob Agents Chemother 48: 1-14, 2004.

25. PerezF,Endimiani A, Hujer KM and Bonomo RA: The continuing challenge of ESBLs. Curr Opin Pharmacol 7: 459-469, 2007.

26. Walsh TR, Toleman MA, Poirel L and Nordmann P Metallo-beta-lactamases: The quiet before the storm? Clin Microbiol Rev 18: 306-325, 2005.

27. Shahi SK, Singh VK and Kumar A: Detection of Escherichia coli and associated $\beta$-lactamases genes from diabetic foot ulcers by multiplex PCR and molecular modeling and docking of SHV-1, TEM-1, and OXA-1 $\beta$-lactamases with clindamycin and piperacillin-tazobactam. PLoS One 8: e68234, 2013.

28. Oyibo SO, Jude EB, Tarawneh I, Nguyen HC, Harkless LB and Boulton AJ: A comparison of two diabetic foot ulcer classification systems: The Wagner and the University of Texas wound classification systems. Diabetes care 24: 84-88, 2001.

29. Bauer AW, Perry DM and Kirby WM: Single-disk antibiotic-sensitivity testing of Staphylococci: An analysis of technique and results. AMA Arch Intern Med 104: 208-216, 1959.

30. Clinical and Laboratory Standards Institute (CLSI). Performance Standards for Antimicrobial Susceptibility Testing: Twenty-first Informational Supplement (M100-S21). CLSI, Wayne, PA, 2011.

31. Singhal S, Mathur T, Khan S, Upadhyay DJ, Chugh S, Gaind R and Rattan A: Evaluation of methods for AmpC beta-lactamase in gram negative clinical isolates from tertiary care hospitals. Indian J Med Microbiol 23: 120-124, 2005.

32. Yong D, Lee K, Yum JH, Shin HB, Rossolini GM and Chong Y: Imipenem-EDTA disk method for differentiation of metallo-beta -lactamase-producing clinical isolates of Pseudomonas spp. and Acinetobacter spp. J Clin Microbiol 40: 3798-3801, 2002.

33. Shahcheraghi F, Nikbin VS and Feizabadi MM: Prevalence of ESBLs genes among multidrug-resistant isolates of Pseudomonas aeruginosa isolated from patients in Tehran. Microb Drug Resist 15: 37-39, 2009

34. Fang H, Ataker F, Hedin G and Dornbusch K: Molecular epidemiology of extended-spectrum beta-lactamases among Escherichia coli isolates collected in a Swedish hospital and its associated health care facilities from 2001 to 2006. J Clin Microbiol 46: 707-712, 2008

35. Dallenne C, Da Costa A, Decré D, Favier C and Arlet G: Development of a set of multiplex PCR assays for the detection of genes encoding important beta-lactamases in Enterobacteriaceae. J Antimicrob Chemother 65: 490-495, 2010.

36. Boyd DA, Tyler S, Christianson S, McGeer A, Muller MP, Willey BM, Bryce E, Gardam M, Nordmann P and Mulvey MR: Complete nucleotide sequence of a 92-kilobase plasmid harboring the CTX-M-15 extended-spectrum beta-lactamase involved in an outbreak in long-term-care facilities in Toronto, Canada. Antimicrob Agents Chemother 48: 3758-3764, 2004.

37. Monstein HJ, Ostholm-Balkhed A, Nilsson M, Nilsson M, Dornbusch K and Nilsson L: Multiplex PCR amplification assay for the detection of blaSHV, blaTEM and blaCTX-M genes in Enterobacteriaceae. APMIS 115: 1400-1408, 2007.

38. Rodrigues BT, Gilhotra RA, Vangaveti VN and Malabu UH: Prevalence and risk factors of lower limb amputation amongst diabetic food ulcer patients at the Townsville Hospital. Annals of the ACTM 15: 57, 2014.

39. Stockl K, Vanderplas A, Tafesse E and Chang E: Costs of lower-extremity ulcers among patients with diabetes. Diabetes Care 27: 2129-2134, 2004.

40. Gardner SE, Hillis SL, Heilmann K, Segre JA and Grice EA: The neuropathic diabetic foot ulcer microbiome is associated with clinical factors. Diabetes 62: 923-930, 2013.
41. Lipsky BA, Berendt AR, Deery HG, Embil JM, Joseph WS, Karchmer AW, LeFrock JL, Lew DP, Mader JT, Norden C, et al: Diagnosis and treatment of diabetic foot infections. Clin Infect Dis 39: 885-910, 2004

42. Monteiro-Soares M, Boyko EJ, Ribeiro J, Ribeiro I and Dinis-Ribeiro M: Risk stratification systems for diabetic foot ulcers: A systematic review. Diabetologia 54: 1190-1199, 2011.

43. James GA, Swogger E, Wolcott R, Pulcini ED, Secor P, Sestrich J, Costerton JW and Stewart PS: Biofilms in chronic wounds. Wound Repair Regen 16: 37-44, 2008.

44. Mantey I, Hill R, Foster A, Wilson S, Wade JJ and Edmonds ME: Infection of foot ulcers with Staphylococcus aureus associated with increased mortality in diabetic patients. Commun Dis Public Health 3: 288-290, 2000.

45. Dang CN, Prasad YD, Boulton AJ and Jude EB: Methicillin-resistant Staphylococcus aureus in the diabetic foot clinic: A worsening problem. Diabet Med 20: 159-161, 2003.

46. Gadepalli R, Dhawan B, Sreenivas V, Kapil A, Ammini AC and Chaudhry R: A clinico-microbiological study of diabetic foot ulcers in an Indian tertiary care hospital. Diabetes care 29: 1727-1732, 2006.

47. Trivedi U, Parameswaran S, Armstrong A, Burgueno-Vega D, Griswold J, Dissanaike S and Rumbaugh KP: Prevalence of Multiple Antibiotic Resistant Infections in Diabetic versus Nondiabetic Wounds. J Pathog 2014: 173053, 2014.

48. Richard JL, Sotto A and Lavigne JP: New insights in diabetic foot infection. World J Diabetes 2: 24-32, 2011.

49. Satola SW, Lessa FC, Ray SM, Bulens SN, Lynfield R, Schaffner W, Dumyati G, Nadle J and Patel JB; Active Bacterial Core surveillance (ABCs) MRSA Investigators: Clinical and laboratory characteristics of invasive infections due to methicillin-resistant Staphylococcus aureus isolates demonstrating a vancomycin MIC of 2 micrograms per milliliter: Lack of effect of heteroresistant vancomycin-intermediate $S$. aureus phenotype. J Clin Microbiol 49: 1583-1587, 2011.

50. Harish BN, Menezes GA, Shekatkar S and Parija SC: Extended-spectrum beta-lactamase-producing Klebsiella pneumoniae from blood culture. J Med Microbiol 56: 999-1000, 2007.

51. Parveen RM, Khan MA, Menezes GA, Harish BN, Parija SC and Hays JP: Extended-spectrum $\beta$-lactamase producing Klebsiella pneumoniae from blood cultures in Puducherry, India. Indian J Med Res 134: 392-395, 2011.

52. Umadevi S, Joseph NM, Kumari K, Easow JM, Kumar S, Stephen S, Srirangaraj S and Raj S: Detection of extended spectrum beta lactamases, AmpC beta lactamases and metallobetalactamases in clinical isolates of ceftazidime resistant Pseudomonas aeruginosa. Braz J Microbiol 42: 1284-1288, 2011.

53. Saderi H, Karimi Z, Owlia P, Bahar MA and Rad SMBA: phenotypic detection of metallo-beta-lactamase producing Pseudomonas aeruginosa strains isolated from burned patients. Iranian Journal of Pathology 3: 20-24, 2008.

54. Bukhari SZ, Ahmed S and Zia N: Antimicrobial susceptibility pattern of Staphylococcus aureus on clinical isolates and efficacy of laboratory tests to diagnose MRSA: A multi-centre study. J Ayub Med Coll Abbottabad 23: 139-142, 2011.

55. Šeputienè V, Linkevičius M, Bogdaitė A, Povilonis J, Plančiūnienè R, Giedraitiene A, Pavilonis A and Sužiedèliené E: Molecular characterization of extended-spectrum $\beta$-lactamase-producing Escherichia coli and Klebsiella pneumoniae isolates from hospitals in Lithuania. J Med Microbiol 59: $1263-1265,2010$.

56. Bali EB, Accedil L and Sultan N: Phenotypic and molecular characterization of SHV, TEM, CTX-M and extended-spectrum-lactamase produced by Escherichia coli, Acinobacter baumannii and Klebsiella isolates in a Turkish hospital. African Journal of Microbiology Research 4: 650-654, 2010.

57. Umadevi S, Kandhakumari G, Joseph NM, Kumar S, Easow JM, Stephen S and Singh UK: Prevalence and antimicrobial susceptibility pattern of ESBL producing gram negative bacilli. J Clin Diagn Res 5: 236-239, 2011. 